\title{
MEKANISME PRAKTEK JUAL BELI IJON DI DESA MANISAK KECAMATAN RANTO BAEK
}

\author{
PAUZIAH NUR LUBIS, \& ZUL ANWAR AJIM HARAHAP \\ IAIN Padangsidimpuan \\ Email: zulanwar@iain-padangsidimpuan.ac.id \\ DOI: http://dx.doi.org/10.24952/tazkir.v5i1.2017
}

\begin{abstract}
In this Era, many found buying and selling which is carried out by the society starting from legal buying and selling, buying and selling defective, which was canceled in Islamic norms. The fact is that people are already familiar with buying and selling Ijon especially in Manisak village. The mechanism of the practice of buying and selling Ijon that was carried out in the form of traders directly coming to the fields to see the fruits. But buying and selling like this according to Shariah economic law is a broken sale and purchase because doing transactions that are not yet ripe for fruit and still in the trunk, even though both parties have agreed and agree together against buying and selling transactions of this Ijon. So there is a possibility of change to fruits that are still in the stems. Then it will harm the trader or buyer because there is a change in the quality of the fruit, because it's still waiting for the ripe fruit from the stem.
\end{abstract}

Keywords: Buy and sell, and Ijon

\begin{abstract}
Abstrak
Dalam perkembangan zaman saat ini, banyak dijumpai jual beli yang dilakukan masyarakat mulai dari jual beli yang sah, jual beli beli yang rusak, yang dibatalkan dalam kaidah-kaidah Islam. Faktanya masyarakat sudah mengenal jual beli ijon khususnya di Desa Manisak. Mekanisme praktek jual beli ijon tersebut terlaksana yakni berupa pedagang langsung datang ke ladang untuk melihat buah-buahan, dan berjumpa pemiliknya untuk melakukan kesepakatan antara pemiliki dengan pedagang, transaksi jual beli dilakukan dilokasi pohon buah itu berada. Namun jual beli seperti ini menurut Hukum ekonomi syari'ah merupakan jual beli yang rusak karena melakukan transaksi yang terhadap buah yang belum matang dan masih berada di batangnya, walaupun kedua belah pihak sudah menyetujui dan menyepakai dengan suka sama suka terhadap transaksi jual beli Ijon ini. Sehingga ada kemungkinan terjadi perubahan kepada buah-buahan yang masih di batangnya. Maka akan merugikan pedagang atau pembeli karena terjadi perubahan kepada kualitas buah, karena masih menunggu buah matang dari batangnya.
\end{abstract}

Kata Kunci: Jual Beli, dan Ijon 
150 | TAZKIR: Jurnal Penelitian Ilmu-ilmu Sosial dan Keislaman

Vol. 05 No. 1 Juni 2019

\section{PENDAHULUAN}

Islam sebagai ajaran yang bersifat rahmatan lil 'alamin, semangatnyabertumpu pada kemaslahatan yang hakiki termasuk syari'atnya dalam bidang muamalah (bisnis). Kaidah fiqih mengatakan bahwa pada prinsipnya hukum muamalah adalah boleh selama tidak ada dalil yang mengharamkannya. Begitu juga dalam kehidupan manusia, jual beli memang merupakan kebutuhan dhoruri yaitu kebutuhan yang tidak mungkin ditinggalkan, sehingga manusia tidak dapat hidup tanpa kegiatan jual beli. ${ }^{1}$

Islam memandang jual beli sebagai sarana tolong menolong sesama manusia. Sebab, transaksi dalam jual beli tidak hanya dilihat sebagai mencari keuntungan semata, tetapi juga dipandang sebagai bantumembantu sesama saudara. Bagi penjual, untuk memenuhi kebutuhan barang yang dibutuhkan pembeli. Sedangkan bagi pembeli, untuk memenuhi kebutuhan akan keuntungan yang sedang di cari oleh penjual. Atas dasar inilah jual beli merupakan aktivitas yang mulia, dan Islam memperkenankannya. ${ }^{2}$

Jual beli sebagai bukti manusia itu makhluk sosial (zoon politicon) yaitu makhluk yang membutuhkan makhluk lain untuk memenuhi kelangsungan hidupnya. Tanpa melakukan jual beli manusia tidak bisa memenuhi kebutuhannya sendiri. Jual beli menjadi kegiatan yang dilakukan dalam kehidupan manusia dalam rangka untuk mempertahankan kehidupan mereka di tengah-tengah masyarakat.

Tujuan dari mu'āmalah adalah terciptanya hubungan yang harmonis (serasi) antara sesama manusia. Dengan demikian terciptalah ketenangan dan ketentraman. ${ }^{3}$ Seperti yang diterangkan ayat di bawah ini:

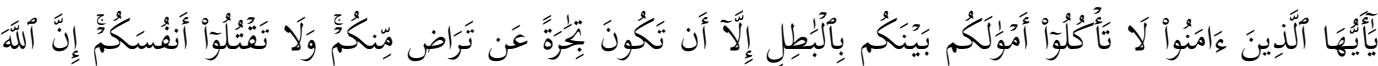
كَانَ بِكُمْ رَحِيما

Artinya:" Hai orang-orang yang beriman, janganlah kamu saling memakan harta sesamamu dengan jalan yang batil, kecuali dengan jalan perniagaan 1994), hlm. 57

${ }^{1}$ Nazar bakri, Problematika Pelaksanaan Figh Islam(Jakarta: PT Raja Grafindo persada,

${ }^{2}$ Nazar bakri Problematika Pelaksanaan.,hlm. 57.

${ }^{3}$ Nazar bakri, Problematika Pelaksanaan, hlm.58 
yang Berlaku dengan suka sama-suka di antara kamu. Dan janganlah kamu membunuh dirimu. Sesungguhnya Allah adalah Maha Penyayang kepadamu". (QS. an-Nisā : 29)

Jual beli dalam Islam harus lengkap rukun jual beli sehingga dapat dijadikan sebagai jual beli yang sah, maka harus ada penjual, pembeli, ijab kobul,dan barang yg di perjual belikan. ${ }^{5}$ Kemudian syarat barang (objek) yang di perjualbelikan harus jelas dan ada empat yang menjadi syarat barang dalam jual beli, yaitu barang yang diperjual belikan harus ada, barang yang diperjual belikan adalah harus yang bernilai, barang tersebut harus milik sendiri, dan barang yang akan dijual bisa diserahkan pada saat transaksi ${ }^{6}$

Perkembangan jenis dan bentuk $m u^{\prime}$ àmalah yang dilaksanakan manusia sejak dulu sampai saat ini terus berkembang sejalan dengan perkembangan kebutuhan dan pengetahuan manusia itu sendiri dalam memenuhi kebutuhan masing-masing. ${ }^{7}$ Manusia mengembangkan ilmu pengetahuan dan teknologi sesuai perkembagan zaman saat ini, sehingga persoalan jual beli yang terjadi dalam masyarakat semakin luas. Salah satunya adanya jual beli ijon (jual beli tanaman, buah-buahan, yang belum siap untuk dipanen). ${ }^{8}$

Permasalahan jual beli ijon menjadi pertentangan di kalangan para Fuqaha mengingat di dalam jual beli ijon sendiri terdapat banyak permasalahan baik dari perluasan hukum yang sudah ada maupun adanya ijon dalam bentuk lain. Jual beli ijon ini masih sangat kerap kita temui pada masyarakat pedesaan, dan praktek yang seperti ini lebih banyak berlaku pada buah-buahan. ${ }^{9}$

Ulama mazhab sepakat membeli buah-buahan yang belum ada di pohonnya tidak sah. Sedangkan menjual buah-buahan yang belum tampak manfaatnya (ijon) para ulama berbeda pendapat. Menurut ulama

${ }^{4}$ Kementerian Agama RI, Alquran dan Terjemahannya (Depok: Sabiq, 2009), hlm. 83

5 Wardani, Figh Ekonomi Syari'ah: Figh Muamalah (Jakarta: PT Kencana Perdana Media 2013), hlm. 102

${ }^{6}$ Wardani, Figh Ekonomi Syari'ah: Figh...., hlm. 102

${ }^{7}$ Nazar bakri, Problematika Pelaksanaan,., hlm. 58

${ }^{8}$ Nazar bakri, Problematika Pelaksanaan....,hlm. 58

${ }^{9}$ Nazar bakri, Problematika Pelaksanaan.... hlm. 58 
152 | TAZKIR: Jurnal Penelitian Ilmu-ilmu Sosial dan Keislaman

Vol. 05 No. 1 Juni 2019

maliki, syafi'i dan lain-lain tidak membolehkannya. Berdasarkan hadis berikut ini: ${ }^{10}$

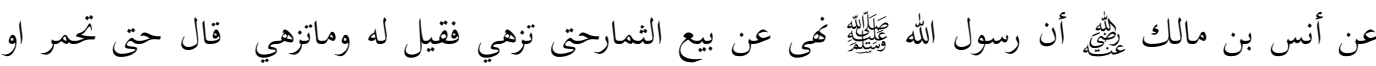

Artinya: "Dari Anas, bahwa Rasulullah SAW melarang menjual buah-buahan sebelum matang. Ada yang bertanya, bangaimana matangnya? beliau menjawab, hingga memerah atau menguning."11

Menurut Abu Hanifah bahwa jual beli ijon tersebut dibolehkan. Hanya saja menurut dia sipembeli harus memetiknya, bukan dari segi penjualan sesuatu yang belum dilihatnya, tetapi dari segi larangan menjualnya sebelum bercahaya sama sekali. Sebagaimana Hadist Rasulullah SAW di bawahini: ${ }^{12}$

$$
\text { أن رسول الله صلى عليه وسلم غیى عن بيع الثمار حتى بيدو صلاحها. فهى البائع والمشتري }
$$

Artinya: "Sesungguhnya Rasulullah SAW melarang menjual buah-buahan hingga tampak kebaikannya (matang). Beliau malarang si penjual dan pembeli."13

Dalam masyarakat kita terdapat suatu kekeliruan bahwa pohon yang baru berkembang dan buah buahan yang belum berbuah sudah diperjual belikan. Bermula dari sinilah perbedaan pendapat dikalangan ulama/mazhab dalam menetapkan kebolehan dari hukum jual beli ijon. ${ }^{14}$

Sepintas diamati yang terjadi dalam masyarakat bahwa jual beli yang terjadi khusunya di Desa Manisak Kecamatan Ranto Baek, memang sama dengan jual beli pada umumnya. Namun, dalam jual beli ijon di Desa Manisak Kecamatan Ranto Baek, mereka melakukan praktek jual beli ijon ini tidak sesuai dengan konsep jual beli, dimana jual beli ijon yang di praktekan di Desa Manisak sudah diperjualbelikan buah yang belum

${ }^{10} \mathrm{Abu}$ Abdullah Muhammad Bin Yasid Ibnu Majah, Tarjemahan Sunan Ibnu Majah (Semarang: CV. Asy Syifa', 1993)

${ }^{11}$ Imam Al-Mundziri, Hadis Shahih Muslim(Jakarta:Pustaka Amani, 2003), hlm. 510

${ }^{12}$ Wahbah az-zuhaili, Figh Islam Wa-adillatuhu (Jakarta:Gema Insani, 2011), hlm, 150

${ }^{13}$ Imam Al-Mundziri, Hadis Shahih Muslim, hlm. 510

${ }^{14}$ Nazar bakri, Problematika Pelaksanaan....,hlm. 58 
masak atau belum nampak kematangannya, kemudian mereka melakukan praktek demikian dengan membayar uangnya ketika akad.

\section{METODE PENELITIAN}

Lokasi penelitian ini dilakukan di Desa Manisak Kecamatan Ranto Baek Kabupaten Mandailing Natal. Waktu penelitian mulai 25 Juni 2018 sampai data yang dibutuhkan penelitian ini sudah lengkap. Jenis penelitian ini juga adalah jenis penelitian lapangan (field research) yaitu dengan menggunakan informasi yang diperoleh dari sasaran penelitian yang selanjutnya disebut informasi/responden melalui instrument pengumpulan data seperti dokumentasi, wawancara, observasi, dan sebagainya. ${ }^{15}$

Sumber data dalam penelitian ini ada dua yaitu sumber data primer dan sumber data sekunder. Data primer diperoleh langsung dari masyarakat yang melakukan praktek jual beli ijon di Desa Manisak Kecamatan Ranto Baek Kabupaten Mandailing Natal. Sedangkan data sekunder diperoleh dari tokoh adat dan alim ulama, hasil karya para ahli hukum berupa buku-buku, hasil-hasil penelitian terdahulu, buku-buku reverensi, majalah hukum, pendapat-pendapat para sarjana yang berhubungan dengan pembahasan penelitian ini.

Untuk mengumpulkan data yang dibutuhkan dari penelitian lapangan, instrumen yang digunakan untuk memperoleh data-data penelitian ini adalah wawancara observasi, dan dokumentasi. Teknik uji keabsahan data melalui perpanjangan keikutsertaan, ketekunan pengamatan, dan triangulasi.

\section{HASIL PENELITIAN}

\section{Mekanisme Praktek Jual Beli Ijon di Desa Manisak Kecamatan Ranto Baek}

Pada umumnya pelaksanaan jual beli yang di Desa Manisak si pembeli datang langsung melihat buah ke ladang pemilik kebun. Pembeli datang untuk melihat kondisi buahnya, memperkirakan berapa buah yang ada di pohon, dan menaksir berapa harga yang cocok untuk membeli buah bagi pemiliknya. 
154 | TAZKIR: Jurnal Penelitian Ilmu-ilmu Sosial dan Keislaman

Vol. 05 No. 1 Juni 2019

Dalam transaksi jual beli yang dilakukan oleh masyarakat Desa Manisak antara pemilik buah-buahan dengan pembeli sebagai pedagang harus memiliki tempat jual beli sebagai tempat transaksi, proses pengambilan buah, dan pandangan ulama begitu juga dengan tokoh adat yang ada di masyarakat yang menjadi pandangan bagi anggota masyarakat.

Berdasarkan wawancara dengan Ibu Nur Satiah mengatakan tempat transaksi jual beli antara penjual dan pembeli dilakukan di rumah karena pohon yang berbuah itu ada di belakang rumahnya. Kami melihat langsung pohon yang berbuah walaupun itu berada di belakang rumah. ${ }^{16}$

Observasi yang dilakukan dengan Ibu Nur Satiah bahwa kebunnya ada di belakang rumah, dari jendala rumah pun sudah terlihat pohonnya.Namun untuk lebih jelasnya kami langsung ketempat kebunnya untukmelihat secara langsung pohonnya serta buahnya. ${ }^{17}$

Wawancara dengan Bapak Ihsan mengatakan bahwa ketika buahbuahan mulai masak di pohonnya, pembeli akan datang kerumahnya untuk menanyakan buahnya akan dijual atau tidak dijual. Kemudian, karena pohon yang berbuah tempat di kebun. Saya dan penjual berangkat ke kebun untuk melihat langsung keadaan buahnya, jumlah buahnya, dan ukuran buahnya yang dihitung dengan cara taksiran. Setelah ada kecocokan maka transaksi jual beli akan dilakukan di kebun tempat dimana buahnya berada. ${ }^{18}$

Observasi yang dilakukan bahwa para petani yang ada di Desa Manisak melakukan transaksi jual beli buah-buahan dimana pohonnya berada.Ini dilakukan supaya tidak terjadi penipuan, dan kedua belah pihak sama-sama mendapat keuntungan. ${ }^{19}$

Berdasarkan uraian di atas tempat menjadi akad dalam jual beli di buah ini bervariasi. Akad bisa dilakukan di rumah kedua belah pihak, dan akad bisa juga terjadi di kebun setelah pembeli melihat buah yang ada di batangnya. Tergantung kesepakatan kedua belah pihak antara pemilik buah dengan pedagang.

${ }^{16}$ Ibu Nur Satiah, Petani Warga Desa Manisak, Wawancara, tanggal 08 Juli 2018

${ }_{17}$ Observasi, Terjun Melihat Lokas iPohon yang Berbuah, tanggal 08 Juli 2018

${ }^{18}$ Bapak Ihsan, Petani Warga Desa Manisak, Wawancara, tanggal 08 Juli 2018

${ }^{19}$ Observasi, Terjun Melihat Lokasi Pohon yang Berbuah, tanggal 08 Juli 2018 
Proses pengambilan buah yang dilakukan oleh pedagang setelah terjadi kesepakatan kedua belah pihak, pedagang menurunkan buah yang sudah matang dari pohonnya, sedangkan buah yang belum matang ditunggu sampai masak dan itu biasanya menunggu 1 bulan sampai 45 hari. Harga buah perbatangnya tergantung dari jumlah buah yang ada, dan kualitas buahnya. Pedagang membeli buah perbatang bervariasi mulai dari Rp. 250.000 sampai Rp. 500.000. ${ }^{20}$

Upaya alim ulama dan tokoh adat terhadap yang melakukan praktek jual beli ijon yaitu menyampaikan kepada masyarakat dalam menjual buah-buahan yang masih berada di batangnya, supaya mengajak pedagang sebagai pembeli untuk melihat langsung keadaan buahnya walaupun itu jauh dari kampung. Ini bertujuan supaya tidak terjadi penipuan kepada pedagang sebagai pembeli. ${ }^{21}$

Untuk menghindari penipuan dan kekecewaan kepada pedagang sebagai pembeli untuk musyawarah bersama untuk menentukan harga yang pantas untuk harga buahnya, dengan adanya kesepakatan kedua belah pihak sama-sama mendapat keuntungan. ${ }^{22}$

\section{Tinjauan Hukum Ekonomi Syari'ah Terhadap Praktek Jual Beli Ijon di Desa Manisak Kecamatan Ranto Baek}

Ditinjau dari hukum ekonomi syariah tentang jual beli dalam Fiqh Muamalah mensyaratkan sahnya jual beli, harus memiliki timbangan yang jelas (diketahui dengan jelas berat jelas yang ditimbang), barang dan harga yang jelas dan ridha kedua belah pihak. Adapun syarat objek yang diperjualbelikan harus diketahui (di lihat), barang yang diperjualbelikan harus dapat diketahui banyaknya, beratnya, takarannya, atau ukuranukuran yang lainnya, maka tidaklah sah jual beli yang jika menimbulkan kerugian salah satu pihak.

Transaksi jual beli yang dilakukan oleh para petani di Desa Manisak melakukan transaksi dengan pembeli padahal buahnya belum matang, dan masih menunggu beberapa hari dan bahkan bulan sehingga buahnya bisa diturunkan. Sehingga ada perkiraan buah yang masih di

\footnotetext{
${ }^{20}$ BapakHolid, Pembeli buah-buahan di Desa Manisak, Wawancara, tanggal 18 Juli 2018

${ }^{21}$ BapakMuhammad Idris, Alim Ulama di Desa Manisak,Wawancara, tanggal 10 Juli 2018

${ }^{22}$ BapakMahmud, Alim Ulama di Desa Manisak,Wawancara,tanggal 13 Juli 2018
} 
156 | TAZKIR: Jurnal Penelitian Ilmu-ilmu Sosial dan Keislaman

Vol. 05 No. 1 Juni 2019

batangnya akan rusak karena di ganggu oleh hama dan hewan-hewan hutan. Maka dengan demikian jual beli ijon yang dilakukan masyarakat Desa Manisak tidak sesuai dengan Hukum Ekonomi Syariah, karena dalam jual beli dalam hukum ekonomi syariah objeknya harus jelas, bagus, dan tidak ada lagi perubahan.

Para petani harus mengubah kebiasaan itu dengan tidak menjual buah-buahan sebelum buah bener-benar matang, dan diturunkan dari batangnya.Walaupun sudah suka sama suka, petani harus merujuk kepada hukum ekonomi syariah dalam melakukan transaksi jual beli, untuk mendapatkan jual beli yang sah yang sesuai dengan hukum ekonomi syariah.

\section{KESIMPULAN}

Berdasarkan pembahasan di atas maka dapat disimpulkan bahwa dalam masyarakat Desa Manisak terjadi jual beli ijon, dimana pedagang datang ke ladang untuk melihat buah-buahan, dan berjumpa pemiliknya untuk melakukan kesepakatan antara pemiliki dengan pedagang, tentang harga, transaksi jual beli ijon dilakukan secara langsung di lokasi pohon buah itu berada. Fakta jual beli seperti ini menurut Hukum ekonomi syari'ah termasuk jual beli yang rusak karena melakukan transaksi yang terhadap buah yang belum matang dan masih berada di batangnya, walaupun kedua belah pihak sudah menyetujui dan menyepakai dengan suka sama suka terhadap transaksi jual beli Ijon ini. Sehingga dimungkinkan akan terjadi perubahan kepada buah-buahan yang masih di batangnya. Maka akan merugikan pegadangan karena dimungkinkan terjadi perubahan kepada kualitas buah, karena masih menunggu buah matang dari batangnya. 


\section{DAFTAR PUSTAKA}

Abu Abdullah Muhammad Bin Yasid Ibnu Majah, Tarjemahan Sunan Ibnu Majah, Semarang: CV. Asy Syifa', 1993.

Abuddin Nata, Metode Studi Islam, Jakarta: Raja Grafindo Persada.

Al-Misri, Rafi Yunus, Al-Jami' fi Ushul ar-Riba, ( Damaskus: Dar al-Qalam, 1991)

Al-Misri, Rafi Yunus, Al-Majmu' fi al-Iqtishad al-Islamiy, (Syuria: Daru alMaktabi , 2006)

Al-Qardhawi, DR.Yusuf, , Bai' al-Murabahah li al-Aamir bi asy-Syira' Kama Tajriyah al-Masharif al-Islamiyah, t.tp: (Kuwait: Maktabah Daru alQalam, 1415 H/1994 M.)

Al-Shawy, Muhammad Shalah. Musykilat al-Istitsmar fi al-Bunuk al-Islamiyah wa Kaifa 'Alajaha al-Islam. (Al-Mansurouh: Daru al-wafa', 1990)

Anita Rahmawaty, Ekonomi syariah; T injauan kritis Produk Murabahah dalam perbankan syariah di Indonesia, Jurnal Ekonomi Islam La-Raiba. Desember 2007

Hasanin, Fayad Addul Mun'im,. Mausu'ah al-Iqtishad al-Islami “Bay' almurabahah fi al-mashraf al-islamiyah". jilid, 3 (Kairo: Darussalam, 2009)

Hendry, Arison, Perbankan Syariah: Perspektif Praktisi, (Jakarta: Muamalat Institute, 1999)

Imam Al-Mundziri, Hadis Shahih Muslim, Jakarta:Pustaka Amani, 2003.

Kementerian Agama RI, Alquran dan Terjemahannya, Depok: Sabiq, 2009.

Mannan, Muhammad Abdul, (terj), M, Nastangin, Teori dan Praktek Ekonomi Islam, (Yogyakarta: Dana Bakti Wakaf, 1995)

Muhammad. Teknik Perhitungan Bagi hasil dan Profit Margin Pada Bank Syariah. ( Yogyakarta: UII press, 2004)

Nazar bakri, Problematika Pelaksanaan Figh Islam, Jakarta: PT Raja Grafindo persada, 1994. 
158 | TAZKIR: Jurnal Penelitian Ilmu-ilmu Sosial dan Keislaman

Vol. 05 No. 1 Juni 2019

Shalahuddin, Ceccep, M.As Produk Investasi Bank Islam Teori dan Praktek "Murabahah (jual beli dengan menentukan keuntukan dimuka". (Kairo: PAKEIS ICMI Orsat Kairo, 2005)

Sjahdeini, Sutan Remy.. Perbankan dan Kedudukannya dalam Tata Hukum Perbankan Indonesia, (Jakarta: Pustaka Utama Grafiti, 1999)

Wahbah az-zuhaili, Figh Islam Wa-adillatuhu, Jakarta:Gema Insani, 2011.

Wardani, Figh Ekonomi Syari'ah: Fiqh Muamalah, Jakarta: PT Kencana Perdana Media 2013. 